\title{
Do farm-level technical efficiency and welfare complement each other? Insight from Ghana's cocoa industry
}

\author{
Gideon Danso-Abbeam ${ }^{1,2,3^{*}}$ and Lloyd J. S. Baiyegunhi ${ }^{2}$
}

\author{
*Correspondence: \\ dansoabbeam@uds.edu.gh; \\ dansoabbeamG@ukzn.ac.za \\ ${ }^{1}$ Department of Agricultural \\ and Resource Economics, \\ University for Development \\ Studies, Tamale, Ghana \\ Full list of author information \\ is available at the end of the \\ article
}

\begin{abstract}
Technical inefficiency persists in Ghana's cocoa farms. Farm-level guidelines from empirical studies are essential to inform programmes dealing with this challenge and subsequently improves farmers' welfare. This study evaluates the two-way effects of technical efficiency and welfare using Data Envelopment Analysis (DEA) and Conditional Mixed-process (CMP). The study reveals that, with no additional inputs, farmers have the potential of increasing their output by an average of 56\% (overall technical efficiency) with mean pure technical and scale efficiencies estimated at $76 \%$ and $58 \%$, respectively. Observed inefficiency in the Ghanaian cocoa farms is due to both inefficient utilization of inputs and farmers' inability to operate at the most productive scale size. Furthermore, findings from the study indicated that improved technical efficiency and welfare of smallholder cocoa farmers are crucial for the sustainable growth of Ghana's cocoa sector as farmers' efficiency and welfare significantly complement each other. In other words, improved welfare enhances technical efficiency, and higher technical efficiency score translates into better welfare. Hence, farm-level policies such as inputs subsidy programmes, training farmers on the proper application of agrochemicals, among others to enhance farm efficiency should be strengthened since efficiency is tied to household welfare. Moreover, investment in education targeted at farmers to improve their managerial and technical capacities will enhance their ability to optimize the operational size of the cocoa production system, and subsequently improve their welfare.
\end{abstract}

Keywords: Conditional Mixed-process (CMP), Data Envelopment Analysis (DEA), Ghana's cocoa industry, Technical efficiency, Welfare

\section{Introduction}

From the time cocoa cultivation was introduced as a farming business in 1897 in Ghana, the crop has been an essential source of livelihood for most of the rural folks in the southern part of the country. Not only has the crop been beneficial to smallholder farmers, but it also has a direct influence on Ghana's macroeconomic balances through foreign exchange earnings and improvement in Gross Domestic Product (GDP). For instance, about 790,000 smallholder farmers are engaged in cocoa production and contribute to about 32\% of the total export revenue in 2013 (Ghana Statistical Services [GSS] 2014).

(c) The Author(s) 2020 This article is licensed under a Creative Commons Attribution 40 International License, which permits use, sharing adaptation, distribution and reproduction in any medium or format, as long as you give appropriate credit to the original author(s) and the source, provide a link to the Creative Commons licence, and indicate if changes were made. The images or other third party material in this article are included in the article's Creative Commons licence, unless indicated otherwise in a credit line to the material. If material is not included in the article's Creative Commons licence and your intended use is not permitted by statutory regulation or exceeds the permitted use, you will need to obtain permission directly from the copyright holder. To view a copy of this licence, visit http://creativeco mmons.org/licenses/by/4.0/. 
In 2015, the cocoa sector contributed about US $\$ 631$ million, representing about $1.9 \%$ of Ghana's GDP (Ghana Statistical Service [GSS] 2016). Further, Ghana's cocoa industry has also created many employment opportunities along its value chain through backward and forward linkages. Thus, the cocoa sector is key to the socio-economic development of the country.

Despite the contribution of cocoa to rural livelihoods and macroeconomic balances, the sector is still faced with many challenges. One of the significant challenges is the over-reliance on natural land productivity and expansion in land under cultivation to increase yield (Besseah and Kim 2014). Thus, cocoa production is partly responsible for the destruction of the Ghanaian green forest. As farmlands are exhausted, and the soil loses its quality, there is a decline in agricultural output. Consequently, the industry dependence on the expansion of farmland to boost productivity is not sustainable. Moreover, the fluctuation in cocoa output over the years is an urgent call on the primary stakeholders to designed policies oriented toward sustainable industrial growth. For instance, Ghana achieved a targeted one million metric tonnes in 2010/11 cocoa production year. However, this level has been unsustainable as output has been fluctuating downwards afterwards. A low output growth relative to its potential, coupled with high prices of inputs such as agrochemicals relative to farmers' real income is partly responsible for the fluctuating growth rate in the industry. For cocoa to continue to have its significant impact on the Ghanaian economy, resources available to farmers ought to be optimized.

Casteneda et al. (2018) noted that about $80 \%$ of the extreme poor live in the rural areas of developing countries and their livelihoods are tied farm activities-either from their farms or agricultural wage employment. Thus, their per capita growth and general socioeconomic welfare are also dependent on agricultural productivity. Hence, efficient use of resources to enhance total agricultural productivity is key to boosting income levels and general well-being of farmers. Although Ghana is the leading producer of cocoa next to Ivory Coast, its yield $(\mathrm{kg} / \mathrm{ha})$ is below that of its competitors in the world cocoa industry. For instance, while Ghana's average yield is about 0.4 tonnes/ha, that of Indonesia and Cote d'Ivoire are about 0.85 tonnes/ha and 0.6 tonnes/ha, respectively (FAOStat 2018). With fluctuating output levels and low yields, the efficiency of resource use has become a significant area of study in Africa's cocoa industry, in order to increase productivity and improve farmers' welfare in a sustainable manner. Many empirical studies (Besseah and Kim 2014; Binam et al. 2008; Onumah et al. 2013) have estimated the productivity and technical efficiency levels in cocoa production in Africa and identified sources of farmers' inefficiencies. However, the question these and other studies in technical efficiency fail to answer is whether farm-level technical efficiency translate into welfare gains or welfare translates into technical efficiency gains. In other words, do technically efficient farmers have better welfare or does improved welfare leads to farm-level technical efficiency? Assessing the two-way effect is critical as better welfare may not necessarily lead to efficient farm management. This is because well-endowed farmers may divert their income into other non-farm activities rather than purchasing farm inputs to improve their efficiency. Moreover, though some farmers may be technically efficient, it may not be sufficient to make them "better-off" due to their scale of operations. Therefore, the two-way quantitative effects of farmers' technical efficiency and welfare gains 
come into play. Building on the previous studies, this study examines the relationship between farm-level technical efficiency and farmers' welfare (proxied by consumption expenditure per capiata). To the best of the authors' knowledge, this is the first study in the Ghanaian cocoa industry to examine the effects of technical efficiency on the welfare of farmers and the effects of welfare on technical efficiency. The study aims to establish a premise on which development efforts geared towards the efficient use of resources for improved rural farm welfare are discussed. The study also hopes to fill a gap in existing agricultural literature, particularly in the African cocoa industry.

\section{Theoretical framework and estimation technique}

This section of the study discusses the theoretical framework on which the objectives of the study are premised. The study employed the two-stage econometric technique to achieve its objectives. First, the technical, pure technical and scale efficiencies of each farm household unit were estimated with the Data Envelopment Analysis (DEA) technique. Second, the study employed Tobit regression and Ordinary Least Square (OLS) regression models with endogenous covariate (to correct for endogeneity) within the framework of Conditional Mixed-process (CMP) to estimate the two-way quantitative effects of technical efficiency and welfare, respectively. ${ }^{1}$

\subsection{Technical efficiency estimation with DEA approach}

DEA is a non-parametric approach that uses linear programming technique to measure the efficiency of decision-making units (DMU) such that the observed input-output vectors are enveloped as tightly as possible (Lee et al. 2009). In DEA, multiple inputs and output can be considered at the same time, with no assumption of the empirical specification or functional form and data distribution. There are two types of DEA, namely input-oriented and the output-oriented DEA. The input-oriented DEA minimizes the input requirements for at least a given output level while the output-oriented maximizes the output levels for a given input (without requiring additional inputs). DEA can further be sub-divided in terms of return-to-scale through the addition of weight constraints. Originally, Charnes et al. (1978) proposed a constant return-to-scale (CRS) for the measurement of efficiency where all DMUs operate at their optimal scale level. Later, efforts were made to break down the efficiency of the DMUs into components in other to identify specific sources of inefficiencies. Banker et al. (1984) introduced the concept of a variable return-to-scale (VRS) measurement of efficiency where the overall efficiency can be subdivided into technical and scale efficiencies. Technical efficiency refers to the ability of DMU to produce a given output with a minimum set of inputs (input-oriented) or using a given set of inputs to produce a maximum output level (an output-oriented) (Coelli et al. 2005). A DMU is said to achieve scale efficiency when it operates at an optimal scale. The fundamental principles of calculating the efficiency of DMUs is to construct a frontier, where all efficient DMUs lie, and those found below the

\footnotetext{
1 The Tobit regression model with endogenous covariate was used to estimate the impact of welfare on technical efficiency while the OLS was used to estimate the impact of technical efficiency on welfare. The two were estimated separately using the CMP estimator.
} 
frontier are considered inefficient. The efficiency index ranges between zero (fully inefficient) and one (fully efficient).

DEA initially emerged as a practical technique of measuring efficiency and sustainability of industrial production systems (Ullah and Perret 2014). However, recently, DEA has been used in agricultural production sectors following the pioneer works of De Koeijer et al. (2002) and Reig-Martinez and Picazo-Tadeo (2004). This was motivated by the heterogeneity of smallholder farmers, particularly in developing countries, who are less likely to exhibit a uniform production function rendering stochastic frontier technique of estimating efficiency less appropriate. In this vein, the study used DEA to generate technical efficiency index for smallholder cocoa farmers in Ghana. Agricultural production in general and cocoa production, in particular, is such that farmers do have less control over output but more control over the quantities of inputs used. Hence, the input-oriented efficiency model was applied in this study. As noted by Coelli et al. (2005), the decision on which orientation to use depends on which side of the production system (input or output) the DMU has more control over. Previous studies such as; Davidova and Latruffe (2003), Krasachat (2004), and Reig-Martinez and Picazo-Tadeo (2004), and recent studies such as Ogada et al. (2014b), Ullah and Perret (2014) and Rahman and Awerije (2015) applied input-oriented DEA in agricultural production systems.

The input-oriented DEA is also called CCR-model named after the initials of Charnes et al. (1978) who developed the model. In the CCR-model, a $j$ th cocoa farm household uses the input vector $X=(1,2, \ldots Z), \in R_{+}^{Z}$ to produce a desirable output, $Y=(1,2 \ldots M), \in R_{+}^{M}$. Following Cooper et al. (2007), the technical efficiency (TE) can be calculated using the DEA model;

Minimize $\theta$ subject to;

$$
\begin{array}{r}
\theta \boldsymbol{X}_{\boldsymbol{j}}-\boldsymbol{X}^{/} \lambda \geq 0 \\
\boldsymbol{Y}^{/} \lambda \geq \boldsymbol{Y}_{\boldsymbol{j}} \\
\lambda \geq 0,
\end{array}
$$

where $\theta$ is a scalar and represents the TE score [also known as the overall technical efficiency (OTE)] of the $j$ th cocoa farm household, and $\lambda$ denotes the intensity vector of the weight of the efficient cocoa farmer. The $\lambda$ is an indicator that helps to project an inefficient cocoa farmer to an efficient frontier. The inputs and output used and produce by the farmer, respectively, are represented by $z \times n$ input matrix $X^{\prime}$ and $m \times n$ output matrix $Y^{\prime}$, where $X_{j}$ is an input vector of the $j$ th cocoa farm and $Y_{j}$ is an output vector of the $j$ th cocoa farm. If the above model satisfies the three basic assumptions (convexity, scalability, and free disposability) of the DEA, then the model exhibits a constant returnto-scale. If the assumption of scalability is not satisfied, then the model exhibits variable return-to-scale. Nonetheless, farming is an activity that exhibits a variable return-toscale (VRS) due to its potential economies of scale (Ullah and Perret 2014). Following Banker et al. (1984), adding extra constraint of $\sum \lambda_{j}=1$ to Eq. (1) leads to a VRS frontier. The VRS is also referred to as pure technical efficiency (PTE) and the model is known as BCC model named after the initials of the authors who suggested it (Banker et al. 1984). Unfortunately, BCC model fails to indicate whether an efficient farmer is exhibiting an increasing or a decreasing return-to-scale. To resolve this problem, Cooper et al. (2007) introduced a non-increasing return-to-scale (NIRS) model where a constraint $\sum \lambda \leq 1$ is 
added to Eq. (1). Comparing technical efficiency under constant return-to-scale ( $\left.\mathrm{TE}_{\mathrm{CRS}}\right)$ and technical efficiency under non-decreasing return-to-scale $\left(\mathrm{TE}_{\mathrm{NIRS}}\right)$ specify whether a production unit exhibits increasing return-to-scale or decreasing return-to-scale. If $\mathrm{TE}_{\mathrm{CRS}}<1$ and $\mathrm{TE}_{\mathrm{CRS}}=\mathrm{TE}_{\mathrm{NIRS}}$, then the farmer produces at an inefficiently small output level, and the inefficiency emanates from increasing return-to-scale. On the other hand, if $\mathrm{TE}_{\mathrm{CRS}}<1$ and $\mathrm{TE}_{\mathrm{NIRS}}>\mathrm{TE}_{\mathrm{CRS}}$, then the farmers' inefficiency results from decreasing return-to-scale (Wossink and Denaux 2006).

\subsection{The two-way impact of welfare and technical efficiency}

The study performs a regression analysis on the second stage of the efficiency analysis to estimate the impact of welfare (proxied by consumption expenditure per capita) on farm-level technical efficiency. Technical efficiency indices were regressed on a set of socioeconomic (including the welfare variable), farm-specific, and policy factors to explain the variation in technical efficiency. In many studies, a Tobit regression model has been used due to the censoring nature of the efficiency score as recently done by Ogada et al. (2014a) and previously by Wossink and Denaux (2006). A simplified farm-level technical efficiency model is specified as:

$$
\theta_{i}=f\left(W_{i}, S_{i}, F_{i}, I_{i}, L_{i}\right),
$$

where $\theta_{i}$ denotes the $i$ th farm efficiency score estimated from the DEA approach, $W_{i}$ is welfare indicator, $S_{i}$ is other socioeconomic variables, $F_{i}$ is farm-specific variables, $I_{i}$ is institutional variables, and $L_{i}$ is location-specific variables. Given the nature of the efficiency score, the following conditions will be observed:

$$
\left\{\begin{array}{cc}
\theta_{i}=\theta_{i}^{*} & \text { if } 0<\theta_{i}<1 \\
\theta_{i}=0 & \text { if } \theta_{i} \leq 0 \\
\theta_{i}=1 & \text { if } \theta_{i} \geq 1
\end{array} .\right.
$$

Thus, Tobit regression model could be used to estimate Eq. (2) given the conditions in Eq. (3). Again, to find out whether farmers with improved welfare are technically efficient or not, a simplified OLS model could be used where the welfare indicator $\left(W_{i}\right)$ is now the dependent variable and the technical efficiency score $(\theta)$ as an explanatory variable as specified in Eq. (4):

$$
W_{i}=f\left(\theta_{i}, S_{i}, F_{i}, I_{i}, P_{i}, L_{i}\right),
$$

where variables are as defined earlier.

However, the problem with estimating Eq. (2) directly with Tobit model is that welfare as one of the explanatory variables is assumed to be exogenous while it is potentially endogenous. Thus, while welfare explains variation in technical efficiency, it is by itself been explained by other variables. Hence, estimating without accounting for such endogeneity leads to biased and inconsistent estimates. Likewise, Eq. (4), where estimating with OLS directly could also lead to bias estimates due to endogenous nature of the efficiency score $(\theta)$ as an explanatory variable. 


\subsubsection{The Conditional Mixed-process (CMP)}

The endogeneity nature of welfare and efficiency variables can lead to under or over-estimation of the true impact of welfare on efficiency and the other way round. To account for this possibility, the study employed the Conditional Mixed-process (CMP) estimator proposed by Roodman (2011) to estimate Eqs. (2) and (4) separately. ${ }^{2}$ The CMP is an empire of multi-equation systems with the ability to take a different format of dependent variables. It also controls for both simultaneity and endogeneity where consistent estimates are produced for a recursive system in which all endogenous variables are observed at the right-hand side of the equation (Asfaw and Lipper 2015). Moreover, the CMP has its foundation from the seemingly unrelated regression framework where cross-equations of the error terms are correlated (Makate et al. 2016). From Eq. (2), assuming the determinants of welfare (as an endogenous variable) is given by:

$$
W_{i}=f\left(X_{i}\right),
$$

where $X_{i}$ is a vector of variables (excluding efficiency score in this case) explaining the variation in welfare. Allowing for potential endogeneity of the welfare variable $W_{i}$, Eqs. (2) and (5) can jointly be estimated, and the joint marginal likelihoods can be expressed as follows;

$$
\iint_{\eta_{2} \eta_{5}}\left[\prod L_{5}\left(\eta_{5}\right) \prod L_{2}\left(\eta_{2}\right)\right] f\left(\eta_{5}, \eta_{2}\right) d \eta_{5} d \eta_{2}
$$

where $L_{2}$ and $L_{5}$ are conditional likelihood functions of Eqs. (2) and (5), respectively; $f\left(\eta_{5}, \eta_{2}\right)$ is the joint estimation of the unobserved heterogeneity components. The joint distribution of the unobserved effects $f\left(\eta_{5}, \eta_{2}\right)$ is assumed to be a two-dimensional normal distribution characterized as follows:

$$
\left(\begin{array}{l}
\eta_{5} \\
\eta_{2}
\end{array}\right) \approx N\left(\left[\begin{array}{l}
0 \\
0
\end{array}\right],\left[\begin{array}{c}
\sigma_{5}^{2} \\
\rho_{25} \sigma_{5} \sigma_{2}, \sigma_{2}^{1}
\end{array}\right]\right)
$$

Similarly, the endogenous efficiency score $(\theta)$ in the welfare Eq. (4) is given by:

$$
\theta_{i}=f\left(Z_{i}\right),
$$

where $Z_{i}$ is a vector of explanatory variables (excluding the welfare variable in this case), then Eqs. (4) and (8) could also be jointly estimated by the CMP estimator as elaborated above. The full model is jointly estimated through the conditional mixed process, which utilizes the Geweke, Hajivassiliou, and Keane (GHK) algorithm to consistently estimate the likelihood function in Eq. (6) (Roodman 2011).The main objective for jointly estimating Eqs. (2) and (5), and Eqs. (4) and (8) is to deal with potential self-selection bias. Maitra (2004) noted that joint estimation implies the possibility of non-zero covariance between the error terms of the equations under consideration. For example, Eqs. (2) and (5), thus, $\operatorname{cov}\left(\eta_{5}, \eta_{2}\right) \neq 0$. The joint estimation of Eqs. (2) and (5), and Eqs. (4) and (8) (with correlated errors) allows selectivity bias to be derived from the estimates of the two-way impact of welfare and technical efficiency. Following the arguments of

\footnotetext{
${ }^{2}$ Equations (2) and (4) are estimated separately due to the recursive structure of the CMP estimator. For more details, see Roodman (2011).
} 
Chamberlin et al. (1975) as cited in Makate et al. (2016), a system of equations does not necessarily require a set of instruments for identification. However, for the purpose of a 'good practice', the study included some instrumental variables for the identification of welfare in Eq. (2) and TE in Eq. (4). Instruments for identification must satisfy two conditions. First, they must have a direct correlation with the endogenous variable and second, they must not have a direct correlation with the error term of the outcome variable. In this study, income from other crops and engagement of spouse in non-farm activities were used as instrumental variables for the endogenous variable, welfare in Eq. (5). Thus, these two variables significant influence welfare but redundant in explaning farm efficiency. For Eq. (8), location-specific variables, and frequency of pesticides application were used to instruments the endogenous variable, TE. Similarly, the location-specific variables and frequency of pesticides explain the variation in farm efficiency score but not welfare,

\section{Data collection procedure and description of variables}

The data used for the study was collected from the four-principal cocoa-producing regions in Ghana: Western, Brong-Ahafo, Eastern, and Ashanti regions. These four regions produce about $90 \%$ of Ghana's cocoa (COCOBOD 2016). The regions are deciduous and semi-deciduous rainforest with an annual rainfall varying from an average of $1250 \mathrm{~mm}$ in the Brong-Ahafo to about $1600 \mathrm{~mm}$ in the Western region. All the regions are predominantly rural, the populace depends on agriculture for their livelihoods, and cocoa is the dominant cash crop contributing significantly to the household income. A wide variety of other food crops such as maize, yam, plantain, cassava, cocoyam, and other cash crops such as palm tree, cashew, and rubber are also grown.

Questionnaire administration and interview with the key informants were the two main techniques used for the data collection. The use of two or more techniques in data collection help to triangulate the information gathered (Bless and Higson-Smith 2000). A multi-stage proportionate random sampling technique was followed in selecting districts and villages from each region and farm household from each village. The proportionate sampling was based on the production intensities of the regions under study. In the first stage, four districts from Western region and three districts each from Eastern, BrongAhafo, and Ashanti regions were randomly selected from a list of cocoa-producing districts in respect of the production capacities of the regions. Western region produces about 53\% of Ghana's cocoa, while Ashanti, Brong-Ahafo, and Eastern regions produce about $17 \%, 10 \%$ and $9 \%$, respectively, in the $2015 / 16$ cocoa production season (COCOBOD 2016). Hence, the selection of the four regions for the study. In the second stage, a random sampling was used to select 3-5 villages from the selected districts and 10-16 farm households from each village. The districts and villages were selected with the help of the regional and district offices of COCOBOD, and was also based on production intensities. In total, 183, 121, 110 and 91 farm households were randomly sampled from Western, Ashanti, Brong-Ahafo, and Eastern regions, respectively. The total sample size for the study was 505 cocoa farm households. Some slight modifications were made during pre-testing of the questionnaire to get more pertinent information and upsurge reliability. Key informants such as some heads of departments of COCOBOD district offices 
Table 1 Descriptive statistics of variables used in the models

\begin{tabular}{|c|c|c|c|}
\hline Variable & Description/unit of measure & Mean & SD \\
\hline Output/hectare & Quantity of cocoa beans per hectare in kilograms & 452.61 & 282.78 \\
\hline Welfare & Consumption expenditure per capita (GHÇ) & 2040.91 & 1602.19 \\
\hline \multicolumn{4}{|l|}{ Inputs for DEA analysis } \\
\hline Farm size & Farm size under cocoa in hectare & 2.92 & 1.75 \\
\hline Labor per hectare & Man-days per hectare ( $8 \mathrm{~h} / \mathrm{man}$-day) & 110.34 & 101.45 \\
\hline Fertilizer per hectare & Quantity of fertilizer in kilograms per hectare & 81.19 & 90.44 \\
\hline Pesticides per hectare & Quantity of pesticides in grams per hectare & 1026.07 & 1802.8 \\
\hline \multicolumn{4}{|l|}{ Variables for other models } \\
\hline Gender & Proportion of male-headed households (male $=1$ ) & 0.71 & \\
\hline Household size & Number of members in the household & 6.12 & 2.81 \\
\hline Education & Number of years in formal education & 6.41 & 5.13 \\
\hline Non-farm income & $\begin{array}{l}\text { Proportion of farmer's spouse that engage in off-farm income } \\
\text { (non-farm income }=1 \text { ) }\end{array}$ & 0.44 & \\
\hline Cocoa farm income & Income from cocoa farm in $\mathrm{GH}$ & 8335.01 & 6568.44 \\
\hline Other crops income & Income from other crops in $\mathrm{GH} \zeta$ & 801.66 & 1311.79 \\
\hline Cocoa demonstration farm & $\begin{array}{l}\text { Proportion farmers that had attended cocoa demonstration } \\
\text { farms (attendance }=1 \text { ) }\end{array}$ & 0.39 & \\
\hline Extension service & Number of times farmer received extension services & 1.46 & 1.81 \\
\hline Farm seminar/workshop & $\begin{array}{l}\text { Proportion of farmers that attended farm seminar (attend- } \\
\text { ance }=1 \text { ) }\end{array}$ & 0.485 & \\
\hline Pesticides application & Frequency of pesticides application (count) & 4.62 & 2.68 \\
\hline Number of plots & Count & 1.37 & 0.96 \\
\hline Brong-Ahafo region & Proportion of sample drawn from the region & 0.18 & \\
\hline Eastern region & Proportion of sample drawn from the region & 0.24 & \\
\hline Ashanti region & Proportion of sample drawn from the region & 0.18 & \\
\hline
\end{tabular}

$S D$ standard deviation, GHC Ghana's currency

and community leaders were approached to discuss the cocoa production system, challenges, and opportunities regarding efficient use of resources and rural farm welfare.

The selected variables hypothesized to influence farm-level technical efficiency and welfare was based on the review of past and recent theoretical and empirical efficiency and welfare-related literature. These pieces of literature include; Temoso et al. (2016), Asante et al. (2017), Kabwe et al. (2016), Ogada et al. (2014a), Nyagaka et al. (2010), Owuor and Ouma (2009), Binam et al. (2008), Binam et al. (2004), Karanja et al. (2003), among others. A detailed description of the variables is reported in Table 1.

Table 1 also provides the summary descriptive statistics of the sampled farm households. The average quantity of cocoa output is $425 \mathrm{~kg} / \mathrm{ha}$, and the mean consumption expenditure per capita is GH\$2040.91 (\$US 477.75). ${ }^{34}$ The average farm size, labour/ ha, the quantity of fertilizer used/ha, and pesticides used/ha are 7, 110, 81, and 1026, respectively. On the average, farmers received GH\$8335 (US\$2142) and GH $\$ 801$ (\$206)

\footnotetext{
${ }^{3}$ GH $4.27=1$ US\$, December 2016.

${ }^{4}$ The annual consumption expenditure is the household consumption expenditure for the preceding year covering 12 months. This was based on the cost of food (household consumption of home produced food + purchased food + gift food) and non-food expenditure (medication + education + occasional expenditure like funerals, etc.) during each month and aggregated to annual level. It is then adjusted per adult equivalent to get the per capita consumption expenditure.
} 
Table 2 Distribution of efficiency score of cocoa production in Ghana

\begin{tabular}{|c|c|c|c|c|c|c|}
\hline \multirow[t]{2}{*}{ Efficiency range } & \multicolumn{2}{|l|}{ OTE } & \multicolumn{2}{|l|}{ PTE } & \multicolumn{2}{|l|}{ SE } \\
\hline & Freq. & $\%$ & Freq. & $\%$ & Freq. & $\%$ \\
\hline $20-30 \%$ & 194 & 38.416 & 26 & 5.149 & 105 & 20.792 \\
\hline $31-40$ & 63 & 12.475 & 37 & 7.327 & 44 & 8.713 \\
\hline $41-50$ & 68 & 13.465 & 40 & 7.921 & 49 & 9.703 \\
\hline $51-60$ & 51 & 10.099 & 53 & 10.495 & 45 & 8.911 \\
\hline $61-70$ & 36 & 7.129 & 41 & 8.119 & 55 & 10.891 \\
\hline $71-80$ & 26 & 5.149 & 31 & 6.139 & 70 & 13.861 \\
\hline $81-90$ & 20 & 3.960 & 28 & 5.545 & 44 & 8.713 \\
\hline$>90<100$ & 18 & 3.564 & 39 & 7.723 & 56 & 11.089 \\
\hline Efficient $(=100)$ & 29 & 5.7426 & 210 & 41.5842 & 37 & 7.327 \\
\hline \multicolumn{7}{|l|}{ Efficiency measures } \\
\hline Mean score & & 0.444 & & 0.767 & & 0.584 \\
\hline Standard deviation & & 0.261 & & 0.257 & & 0.273 \\
\hline Minimum & & 0.054 & & 0.206 & & 0.058 \\
\hline Maximum & & 1 & & 1 & & 1 \\
\hline Mean inefficiency & & 0.556 & & 0.233 & & 0.416 \\
\hline Efficiency interval & & $(0.183 ; 0.705)$ & & $(0.510 ; 1.024)$ & & $(0.311 ; 0.87)$ \\
\hline \multicolumn{7}{|l|}{ Return-to-scale (\%) } \\
\hline Increasing RTS & 68.713 & & & & & \\
\hline Decreasing RTS & 24.951 & & & & & \\
\hline Constant RTS & 6.337 & & & & & \\
\hline
\end{tabular}

OTE, PTE and SE denote overall technical efficiency, pure technical efficiency and scale efficiency, respectively

as revenue from cocoa and other crops, respectively. A household head had an average of 6 years of schooling, and there is an average of 6 persons per household.

About $71 \%$ of households are male headed, $44 \%$ had their spouses engaged in nonfarm income activities, 39\% visited cocoa demonstration farms, and $49 \%$ attended cocoa farm seminar. On the average, farmers are managing approximately 2 plots and had their farms sprayed about 5 times with pesticides per cocoa season. ${ }^{5}$ A farmer received an average of 2 extension services in the last cocoa season.

\section{Empirical results and discussion}

\subsection{Efficiency analysis}

The distribution and the summary statistics of the technical efficiency under CRS(TE $\left.\mathrm{CCR}_{\mathrm{R}}\right)$, technical efficiency under VRS $\left(\mathrm{TE}_{\mathrm{BCC}}\right)$ and scale efficiency are presented in Table 2. As stated earlier, a farmer who fails to achieve technical efficiency of one (1) is considered to be relatively inefficient.

TE under the assumption of CRS represents the overall technical efficiency (OTE) measuring inefficiency resulting from input/output configuration and the size of operation (Kumar and Gulati 2008). The pure technical efficiency (PTE) measures inefficiency

\footnotetext{
${ }^{5}$ Frequency of pesticides application consists of a summation of the number of times farmers apply insecticides and fungicides per cocoa season.
} 
emanating from farmers' managerial underperformance. A measure of scale efficiency relates to the ratio of OTE to that of PTE (i.e., $\left.\mathrm{SE}=\mathrm{TE}_{\mathrm{CRS}} / \mathrm{TE}_{\mathrm{VRS}}\right)^{6}{ }^{6}$

The frequency distribution in Table 2 reveals that most cocoa farmers are inefficient. The number of efficient farmers under constant-to-scale (OTE) is 29 representing about 6\%; thus the majority (94\%) of the farmers were inefficient. The 29 efficient farmers together define the efficient frontier and, hence, set the standard for inefficient farmers. These farmers are utilizing their resources very well without or with minimal waste. They are referred to as peers, and their practices are good examples for their inefficient counterparts to replicate. The mean OTE efficiency is about $44 \%$ implying that, by adopting best practices, cocoa farmers can still achieve their output level with the existing technology by potentially reducing their inputs by a substantial average of 56\%. Alternatively, cocoa farmers have the scope of producing as much as 2.27 times $(1 / 0.44)$ of their current production level without altering the quantities of inputs. Using stochastic frontier approach, Onumah et al. (2013) obtained a mean efficiency of $68 \%$ among cocoa farmers in the Eastern Region of Ghana while Ullah and Perret (2014) reported an average OTE of 54\% among small and large cotton farms in Pakistan with DEA approach. However, Kabwe et al. (2016) reported a lower OTE level of $43 \%$ and $31 \%$ among cotton farmers in Zambia using DEA and stochastic frontier, respectively. A large proportion (64\%) of cocoa farmers achieve OTE of $50 \%$ and below while only $30 \%$ of them had more than $50 \%$ efficiency, albeit, they are still inefficient.

However, the number of efficient farmers increased significantly when PTE was used. The mean PTE was estimated to be $76 \%$, high above that of OTE. This is expected because, as noted by Kumar and Gulati (2008) "BCC model forms a convex hull of intersecting planes which envelopes the data points more tightly than CRS conical hull and provides efficiency scores which are greater than or equal to those obtained using CCR model." In addition to 29 farmers that are technically efficient, 181 farmers that were not efficient under CRS have become efficient under VRS. Thus, the total efficient farmers under VRS is 210 representing about $42 \%$. This suggests that technical inefficiency under CRS may be caused by inappropriate scale size rather than poor utilization of resources (managerial inefficiency). However, for those inefficient farmers under VRS, managerial inefficiencies exist. Table 2 further indicates that apart from the $42 \%$ of farmers that are BCC-efficient, about $7 \%$ also achieve scale efficiency with the mean scale efficiency of about $58 \%$.

One of the fundamental objectives of every production unit is to operate with constant return-to-scale (most productive scale size) to maximize profit. DMUs may operate in the region of increasing return-to-scale (IRS) or decreasing return-to-scale (DRS) in the short run. However, in the long-term, they will try to manipulate their operating strategies to move towards CRS where costs and revenue can be optimized. As indicated in Table 2, the $6 \% \mathrm{TE}_{\mathrm{CCR}^{-}}$-efficient farmers operate at the most productive scale size, hence, experience CRS. About $69 \%$ of the cocoa farmers operate below their optimal scale size

\footnotetext{
${ }^{6}$ Overall technical efficiency (OTE) refers to both technical efficiency CRS and $\mathrm{TE}_{\mathrm{CCR}}$, and hence, used interchangeably. Similarly, pure technical efficiency (PTE) refers to both technical efficiency under VRS and $\mathrm{TE}_{\mathrm{BCC}}$, hence, used interchangeably.
} 
Table 3 Determinants of technical efficiency and the two-way impacts of efficiency and welfare

\begin{tabular}{|c|c|c|c|c|c|c|c|c|}
\hline \multirow[t]{3}{*}{ Variable } & \multicolumn{4}{|c|}{ Impact of welfare on efficiency } & \multicolumn{4}{|c|}{ Impact of efficiency on welfare } \\
\hline & \multicolumn{2}{|c|}{$\begin{array}{l}\text { 10TE model } \\
\text { (welfare) }\end{array}$} & \multicolumn{2}{|c|}{$\begin{array}{l}{ }^{2} \text { PTE model } \\
\text { (welfare) }\end{array}$} & \multicolumn{2}{|c|}{$\begin{array}{l}{ }^{3} \text { Welfare model } \\
\text { (OTE) }\end{array}$} & \multicolumn{2}{|c|}{$\begin{array}{l}{ }^{4} \text { Welfare mode } \\
\text { (PTE) }\end{array}$} \\
\hline & ME & SE & ME & SE & ME & SE & ME & SE \\
\hline Gender & -0.010 & 0.031 & $0.135^{\mathrm{a}}$ & 0.052 & & & & \\
\hline Household size & 0.004 & 0.004 & 0.007 & 0.004 & 0.012 & 0.018 & -0.004 & 0.077 \\
\hline Educational attainment & & & & & 0.008 & 0.010 & $0.110^{b}$ & 0.041 \\
\hline Spouse's non-farm income & -0.020 & 0.038 & -0.024 & 0.032 & $0.224^{\mathrm{a}}$ & 0.035 & $0.199^{\mathrm{a}}$ & 0.035 \\
\hline Income from cocoa farm & & & & & $0.188^{\mathrm{a}}$ & 0.048 & $0.262^{\mathrm{a}}$ & 0.050 \\
\hline Income from other crops & -0.001 & 0.002 & 0.002 & 0.007 & $0.009^{b}$ & 0.003 & $0.004^{b}$ & 0.002 \\
\hline Demonstration farm visit & $0.035^{b}$ & 0.016 & -0.010 & 0.015 & & & & \\
\hline Extension contact & 0.008 & 0.006 & 0.000 & 0.006 & $0.021^{b}$ & 0.008 & $0.018^{b}$ & 0.008 \\
\hline Farm seminar attendance & & & & & 0.085 & 0.101 & 0.005 & 0.054 \\
\hline Frequency of pesticides application & $0.028^{c}$ & 0.015 & $0.028^{c}$ & 0.014 & 0.002 & 0.007 & -0.005 & 0.005 \\
\hline Number of farm plots & $-0.045^{\mathrm{a}}$ & 0.014 & 0.016 & 0.012 & & & & \\
\hline Farm size & -0.007 & 0.011 & $0.097^{\mathrm{a}}$ & 0.033 & $0.015^{b}$ & 0.007 & $0.190^{\mathrm{a}}$ & 0.013 \\
\hline East region & $-0.126^{\mathrm{a}}$ & 0.040 & $-0.191^{\mathrm{a}}$ & 0.038 & -0.023 & 0.025 & 0.037 & 0.028 \\
\hline Brong-Ahafo region & -0.029 & 0.060 & $-0.232^{\mathrm{a}}$ & 0.054 & 0.025 & 0.027 & 0.006 & 0.008 \\
\hline Ashanti region & $-0.109^{b}$ & 0.044 & $-0.077^{c}$ & 0.041 & 0.002 & 0.026 & 0.010 & 0.008 \\
\hline Log of welfare & $0.224^{c}$ & 0.134 & $0.940^{\mathrm{a}}$ & 0.307 & & & & \\
\hline OTE (CRS) & & & & & $3.732^{c}$ & 2.047 & & \\
\hline PTE (VRS) & & & & & & & $1.695^{\mathrm{a}}$ & 0.417 \\
\hline Constant & 0.362 & 0.336 & 2.592 & 0.710 & 0.112 & 1.648 & 2.752 & 0.252 \\
\hline /Insig_1 & $-1.367^{a}$ & 0.048 & $-0.898^{\mathrm{a}}$ & 0.211 & 0.006 & 0.492 & $-0.757^{a}$ & 0.164 \\
\hline /Insig_2 & $-1.126^{a}$ & 0.031 & $-1.099^{a}$ & 0.033 & $-1.368^{\mathrm{a}}$ & 0.315 & $-1.408^{\mathrm{a}}$ & 0.031 \\
\hline latanhrho_12 & $-0.252^{c}$ & 0.151 & $1.221^{\mathrm{a}}$ & 0.259 & $-1.807^{\mathrm{a}}$ & 0.521 & $-0.952^{\mathrm{a}}$ & 0.222 \\
\hline
\end{tabular}

and thus, experience IRS. These farmers can improve their level of $\mathrm{TE}_{\mathrm{CCR}}$ by increasing their scale size. The remaining $25 \%$ of farmers operate above their optimal scale level (DRS), hence, downsizing their scale of operation is a better option to enhance their efficiency level. Generally, it is observed that Ghanaian cash crop farmers exhibit increasing return-to-scale. Onumah et al. (2013) and Mensah and Brümmer (2016) reported similar results in Ghana's cocoa and oil palm industry, respectively.

\subsection{Factors explaining variation in farmers' efficiency: OTE and PTE}

The variation in farmers' OTE and PTE could be explained by some socioeconomic, farm-specific and policy or institutional factors. The results are presented in Table 3.

From the results, gender gap exists in measuring farmers' performance under the assumption of VRS. Male farmers were observed to be technically more efficient than their female counterparts.

This could partly be attributed to the tedious nature of cocoa farming which, in principle, is more suitable for male farmers than female farmers. It contradicts the results of Kabwe et al. (2016) where female-headed cotton farmers are more technically efficient 
than male-headed farmers. However, it is in line with Rahman and Awerije (2015) where male farmers are more technically efficient than female farmers under VRS assumption. A visit to farm demonstration correlates positively and significantly with OTE, but have no influence on PTE. Demonstration farms offer an excellent opportunity to farmers to learn new ways of farming to improve their technical and managerial skills. Similarly, the frequency of pesticides application positively and significantly influences OTE and PTE. Pests and diseases have the potential to reduce output considerably. Hence, Cocoa Research Institute of Ghana (CRIG) recommends an application of insecticides and fungicides at least 3 and 6 times per cocoa season, respectively. Thus, farmers that have their farms sprayed more frequently tend to have $2.8 \%$ and $2 \%$ higher OTE and PTE score than those that sprayed their farms less frequently, respectively. Moreover, while the number of farm plots negatively influence OTE, farm size positively and significantly affect PTE. Linh et al. (2017) reported a negative effect of farm size on OTE. The location variables in the two models indicate that farmers located in the Eastern, Brong-Ahafo, and Ashanti regions are less technically efficient under both OTE and PTE assumption than their counterparts in the Western region. ${ }^{7}$ This may partially be attributed to differences in regional climatic features (e.g., an intensity of rainfall, soil conditions, and topography) and market conditions such as input prices.

\subsection{The impact of welfare on efficiency and of efficiency on welfare}

For farm-level policy formulation, it is critical to know the quantitative effects of welfare on efficiency, i.e., if farmers with improved welfare are technically efficient. The consumption expenditure per capita was used as a proxy for farmers' welfare. In Table 3, welfare is included as explanatory variables in OTE and PTE models (1 and 2) after accounting for endogeneity. The second part of Table 3 contains welfare regression models ( 3 and 4 ) where OTE and PTE scores are used as explanatory variables. The reported atanhrho_12 at the bottom of the table indicates a primary measure of endogeneity resulting from selectivity bias. A significant value of atanhrho_12 is an evidence of self-selection bias, and this is observed in all the four models. A significant positive value indicates that some unobserved covariates positively affect the endogenous and the outcome variables. The reverse applies to a negative significant value. In this study, some omitted variables impact negatively on welfare and OTE while others have positive effects on welfare and PTE. For instance, in the welfare models (3 and 4), the negative values of atanhrho_12 are evidence that some unobserved factors are negatively affecting both the outcome variable (welfare) and the endogenous variables (OTE and PTE scores).

The positive coefficient of OTE and PTE of models 1 and 2, respectively, in Table 3 indicates that better welfare improves both OTE and PTE of farmers. Thus, farmers with improved welfare are "better-off" by $0.22 \%$ and $0.94 \%$ regarding efficiency under CRS and VRS, respectively. A plausible explanation for this is that households with better welfare can purchase the right quantity of inputs at the right time, and subsequently improves their efficiency level. Another attributable reason is that, in a typical African society, wealthy households have better access to information and other services such

${ }^{7}$ About the location variables, western region was used a reference category because it is the largest producer of cocoa in Ghana and has the greatest population in the data set. 
as extension services than the poorer households. Similarly, the positive and significant values of OTE and PTE in both models (3 and 4) confirm that high scores of efficiencies (i.e., OTE and PTE) translate into better welfare. This is not surprising as efficient use of resources enables farmers to save cash resources to be used for other productive goods and services, which are vital to their welfare development. In sum, the principle that improvement in farm households' welfare translate into increasing efficiency and increasing efficiency also make farmers' better-off regarding welfare holds, at least, in Ghana's cocoa industry. However, the magnitude of the effects of technical efficiency on welfare is larger than that of welfare on technical efficiency as revealed by the study. Kabwe et al. (2016) found no significant effect of welfare (proxied by productive assets) on technical efficiency probably because of the weak econometric technique used where the study fails to account for potential endogeneity. Other variables such as engagement of spouse in non-farm activities, income from cocoa farm, income from other crops, extension contacts and farm size also exert positive and significant effects on welfare in both models (3 and 4).

\section{Conclusions and recommendations}

This study endeavors to evaluate the extent of technical efficiency and the two-way effects of farm-level efficiency and welfare of smallholder cocoa farmers in Ghana. Improved technical efficiency and welfare of smallholder cocoa farmers are vital for the sustainable growth of the Ghanaian cocoa industry as technical efficiency and welfare significantly complement each other. Results from the study revealed that only $6 \%$ of cocoa farmers are on the frontier in the cocoa production system. On average, farmers have the potential to increase their output by $56 \%$ without increasing their input levels. The primary source of inefficiency emanates from farmers operating below their optimal level (IRS). Hence, farmers can improve their standard of efficiency by up-scaling their size of the operation. The study further revealed that higher technical efficiency score leads to better farm households' welfare and an improved welfare translates into higher efficiency score. Thus, technical efficiency and welfare significantly complement each other.

One of the policy implication of the study's findings is that increasing farm-level efficiency is crucial to sustaining Ghana's target of achieving one million metric tonne of cocoa per year. There will be a concomitant impact on farm households' welfare since efficiency and welfare are complementary. Thus, an urgent call on Ghana Cocoa Board (COCOBOD) to strengthen her existing cocoa farm-level policies such as cocoa Hi-tech programme, payment of better producer prices and bonus payment schemes as means of encouraging farmers to enhance productivity. Creating awareness on the unproductive use of resources can also be the surest avenue to improving farmers' level of efficiency. If farm households are conscious of inefficient use of resources and/or inappropriate farm management practices, then through technical and managerial skill development programs, they could effectively combine inputs to optimize their output. 


\section{Acknowledgements}

The authors are very grateful to the cocoa farmers who sat patiently for hours to answer the detailed interview questions and the enumerators who worked so hard to collect and enter the data set.

\section{Authors' contributions}

GD-A conceptualized the idea, handled the data analysis and the discussion of the results. LJSB supervised the writing of the manuscript, proofread to ensure the quality of the study and contributed to the revised version of the paper. Both authors read and approved the final manuscript.

\section{Funding}

This study did not receive any specific grant from funding agencies in the public, commercial or not-for-profit sectors.

Availability of data and materials

The data that support the findings of this study can be obtained from the authors upon request.

\section{Ethics approval and consent to participate}

Ethical approval and consent to participate is not applicable for this study.

\section{Competing interests}

The authors declare that they have no competing interests.

\section{Author details}

${ }^{1}$ Department of Agricultural and Resource Economics, University for Development Studies, Tamale, Ghana. ${ }^{2}$ Discipline of Agricultural Economics, University of KwaZulu-Natal, Pietermaritzburg, South Africa. ${ }^{3}$ African Centre for Crop Improvement, University of KwaZulu-Natal, Pietermaritzburg, South Africa.

Received: 2 April 2019 Revised: 19 February 2020 Accepted: 29 February 2020

Published online: 09 March 2020

\section{References}

Asante BO, Villano R, Battese GE (2017) Integrated crop-livestock management practices, technical efficiency and technology ratios in extensive small-ruminant systems in Ghana. Livest Sci 201:58-69

Asfaw S, Lipper L (2015) Adaptation to Climate Change and its Impact on Food Security: Evidence from Niger. In: Paper presented at the international conference on agricultural economics, Milan, Italy

Banker RD, Charnes A, Cooper WW (1984) Some models in estimating technical and scale efficiencies in data envelope analysis. Eur J Oper Res 2:429-444

Besseah FA, Kim S (2014) Technical efficiency of cocoa farmers in Ghana. J Rural Dev 37(2):159-182

Binam JN, Tonye J, Wandji N, Nyambi G, Akoa M (2004) Factors affecting the technical efficiency among smallholder farmers in the slash and burn agriculture zone of Cameroon. Food Policy 29:531-545

Binam JN, Gockowski J, Nkamleu GB (2008) Technical efficiency and productivity potential of cocoa farmers in West African countries. Dev Econ XLVI 3:242-263

Bless C, Higson-Smith C (2000) Fundamentals of social research methods: an African perspective, 3rd edn. Juta, Cape Town

Charnes A, Cooper WW, Rhodes E (1978) Measuring the efficiency of decision making units. Eur J Oper Res 2:429-444

COCOBOD (2019) https://cocobod.gh/weakly_purchase.php. Accessed 15 Nov 2019

Coelli TJ, Rao DSP, O'Donnell CJ, Battese GE (2005) An introduction to efficiency and productivity analysis. Springer, New York

Cooper WW, Seiford LM, Tone K (2007) Data envelopment analysis: a comprehensive text with models, applications, references and DEA-Solver software, 2nd edn. Springer Science Business Media, LLC, New York

Davidova S, Latruffe L (2003) Technical efficiency and farm financial management in countries in transition. In: Institut National del recherche' Agronomique working paper series 03-01 (December), 03-01, 1-35

De Koeijer TJ, Wossink GAA, Struik PC, Renkema JA (2002) Measuring agricultural sustainability in terms of efficiency: the case of Dutch sugar beet growers. J Environ Manage 66:9-17

FAOStat (2018) Food and Agriculture Organization. Retrieved from http://www.fao.org/faostat/en/\#data. Accessed 15 Nov 2019

Kabwe S, Namonje T, Chisanga B (2016) Technical efficiency: are Zambian cotton farmers lagging behind. Working paper No. 111. Indaba Agricultural Research Policy Research Instiute (IAPRI), Lusaka, IAPRI

Karanja D, Renkow M, Crawford E (2003) Welfare effects of maize technologies in marginal and high potential regions of Kenya. Agric Econ 29(3):331-341

Krasachat W (2004) Technical efficiencies of rice farms in Thailand: a non-parametric approach. J Am Acad Bus Camb 4:1-2

Lee C, Lee J, Kim T (2009) Defence acquisition innovation policy and dynamics of productive efficiency: a DEA application to the Korean defence industry. Asian JTechnol Innov 17(2):151-171

Linh LT, Lee PP, Peng KC, Chung RH (2017) Factors influencing technical efficiency of rice farms in Dong Thap Province, Vietnam: an application of two-Stage DEA. Am Eurasian J Agric Environ Sci 17(3):245-249

Maitra P (2004) Parental bargaining, health inputs and child mortality in India. J Health Econ 23:259-291

Makate C, Wang R, Makate M, Mango N (2016) Crop diversification and livelihoods of smallholder farmers in Zimbabwe: adaptive management for environmental change. SpringerPlus 5:1135

Mensah A, Brümmer B (2016) Drivers of technical efficiency and technology gaps in Ghana's mango production sector: a stochastic metafrontier approach. Afr J Agric Resour Econ 11(2):101-117

Nyagaka DO, Obare GA, Omiti JM, Nguyo W (2010) Technical efficiency in resource use: evidence from smallholder Irish potato farmers in Nyandarau North District, Kenya. Afr J Agric Res 5(1):1179-1186 
Ogada MJ, Muchai D, Mwabu G, Mathenge M (2014a) Technical efficiency of Kenya's smallholder food crops farmers: do environmental factors matter? Environ Dev Sustain 16:1065-1076

Ogada MJ, Mwabu G, Muchai D (2014b) Farm technology adoption in Kenya: a simultaneous estimation of inorganic fertilizer and improved maize variety adoption decisions. Agric Food Econ 2(1):1-18

Onumah JA, Onumah EE, Alhassan RM, Brümmer B (2013) Meta-frontier analysis of organic and conventional cocoa production in Ghana. Agric Econ Czech 59(6):271-280

Owuor G, Ouma AS (2009) What are the key constraints in technical efficiency of smallholder farmers in Africa? Empirical evidence from Kenya. In: Paper presented at the A paper presented at the 111 EAAE-IAAE conference, University of Kent, Canterbury, UK

Rahman S, Awerije BO (2015) Technical and scale efficiency of cassava production system in Delta State, Nigeria: an application of Two-stage DEA approach. J Agric Rural Dev Trop Subtrop 116(1):59-69

Reig-Martínez R, Picazo-Tadeo A (2004) Analysing farming systems with data envelopment analysis: citrus farming in Spain. Agric Syst 82:17-30

Roodman D (2011) Fitting fully observed recursive mixed-process models with CMP. STATA J 11:159-206

Temoso T, Villano R, Hadley D (2016) Evaluating the productivity gap between commercial and traditional beef production systems in Botswana. Agric Syst 149:30-39

Ullah A, Perret SR (2014) Technical and environmental efficiency analysis of irrigated cotton-cropping systems in Punjab, Pakistan using data envelopment analysis. Environ Manage 54:288-300

Wossink A, Denaux ZS (2006) Environmental and cost efficiency of pesticide use in transgenic and conventional cotton production. Agric Syst 90:312-328

Castaneda A, Doan D, Newhouse D, Nguyen MC, Uematsu H, Azevedo JP. World Bank Data for Goals Group. 2018. A new profile of the global poor. World Development, 101:250-267

Ghana Statistical Service (GSS) (2014) Anual gross domestic product report. Statistics for development and progress. Accra, Ghana.

Ghana Statistical Service (GSS) (2016) GSS report on revised 2015 annual gross domestic product. Accra, Ghana.

Kumar S, Gulati R (2008) An examination of technical, pure technical and scale efficiencies in indian public sector banks using data envelopment analysis. Eurasian J Bus Econ 1(2):33-69

\section{Publisher's Note}

Springer Nature remains neutral with regard to jurisdictional claims in published maps and institutional affiliations.

\section{Submit your manuscript to a SpringerOpen ${ }^{\circ}$ journal and benefit from:}

- Convenient online submission

- Rigorous peer review

- Open access: articles freely available online

High visibility within the field

- Retaining the copyright to your article

Submit your next manuscript at $\gg$ springeropen.com 